This manuscript has been submitted for publication in Science Advances. It has not yet been accepted for publication, and so the final published version may differ from this version. If accepted, the official, published version of this manuscript will be available via the 'Peerreviewed Publication DOI' link.

\title{
An Outsized Role for the Labrador Sea in the Multidecadal Variability of the Atlantic Overturning Circulation
}

Authors: S. G. Yeager ${ }^{1,2 *}$, F. Castruccio ${ }^{1,2}$, P. Chang ${ }^{2,3}$, G. Danabasoglu ${ }^{1,2}$, E. Maroon ${ }^{4}$, J.

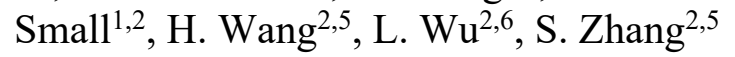

\section{Affiliations:}

${ }^{1}$ National Center for Atmospheric Research; Boulder, CO, USA.

${ }^{2}$ International Laboratory for High Resolution Earth System Prediction; College Station, TX, USA.

${ }^{3}$ Texas A\&M University; College Station, TX, USA.

${ }^{4}$ University of Wisconsin-Madison; Madison, WI, USA.

${ }^{5}$ Ocean University of China; Qingdao, China.

${ }^{6}$ Qingdao Pilot National Laboratory for Marine Science and Technology; Qingdao, China.

*Corresponding author. Email: yeager@ucar.edu

\begin{abstract}
Climate models are essential tools for investigating intrinsic North Atlantic variability related to variations in the Atlantic meridional overturning circulation (AMOC), but recent observations have called into question the fidelity of models that emphasize the importance of Labrador Sea processes. A multi-century pre-industrial simulation that resolves ocean mesoscale eddies has a realistic representation of key observed subpolar Atlantic phenomena, including the dominance of density-space overturning in the eastern subpolar gyre, and thus provides uniquely credible context for interpreting short observational records. Despite weak mean surface diapycnal transformation in the Labrador Sea, multidecadal AMOC variability can be traced to anomalous production of dense Labrador Sea Water with local buoyancy forcing in the interior Labrador Sea playing a significant driving role.
\end{abstract}

One-Sentence Summary: Labrador Sea forcing can dominate multidecadal thermohaline circulation variability in the Atlantic even while contributing minimally to mean circulation strength. 
The Atlantic Ocean is widely believed to be a significant source of intrinsic, low-frequency (LF; decadal and longer timescale) variability in the climate system. Instrumental and paleoclimate proxy records from the pan-Atlantic region show pronounced multidecadal variability that has been ascribed to slow changes in the strength of the Atlantic meridional overturning circulation (AMOC) and associated ocean heat transport into high northern latitudes $(1,2)$. Climate models permit in-depth study of LF climate variability and are necessary for projecting future climate change, but to be credible, they must exhibit consistency with key observations. Recent measurements from the Overturning in the Subpolar North Atlantic Program (OSNAP) have challenged prevailing views about the high latitude drivers of AMOC and raised questions about the fidelity of climate model simulations of North Atlantic processes (3). The OSNAP measurements show that North Atlantic density-space overturning - that is, the transformation of warm, light North Atlantic Current (NAC) water into cold, dense North Atlantic Deep Water (NADW) - takes place predominately in the eastern subpolar gyre, implying a negligible role for Labrador Sea processes in driving AMOC (3). Earlier observational work had posited a minor role for the Labrador Sea in contributing to the density transformation that sustains the AMOC (4), but the OSNAP data allows for direct comparison of the overturning circulation across the Labrador Sea (OSNAP West) to that across the northeastern subpolar gyre (OSNAP East) that clearly reveals the dominance of the latter. Other recent observational studies support the OSNAP results, highlighting the region to the north of the OSNAP East array and to the south of the Greenland-Scotland Ridge (i.e., the Irminger Sea and Iceland Basin) as the key location of NADW formation via surface buoyancy loss (5-7). These findings stand in contrast to climate modeling studies that have long emphasized the link between AMOC strength at lower latitudes and the intensity of Labrador Sea Water (LSW) production, which is often quantified in terms of the strength of deep convection within the Labrador Sea and/or Labrador Sea deep density structure $(1,2)$.

There is therefore considerable uncertainty about the role of the Labrador Sea in Atlantic climate variability. The Labrador Sea density signals that exhibit strong relationships with lower latitude AMOC in climate models $(8)$ could largely originate from surface forcing in the Iceland Basin and Irminger Sea, rather than local diapycnal transformation (9). It is therefore plausible that the Labrador Sea plays a mostly passive role in the mean and variability of AMOC, and that it is only dynamically relevant insofar as its state reflects the cumulative effect of surface forcing over the broad subpolar North Atlantic (SPNA). In addition to serving as an indicator of the strength of SPNA water mass transformation (WMT; see Materials and Methods), deep convection in the Labrador Sea appears to mediate the ventilation and subduction of NADW, and so this region serves as an important entryway into the deep ocean for a variety of tracers even if deep mixing contributes little to AMOC (10). The OSNAP record is short (21-months), and so there is a possibility that the Labrador Sea could play an active role in the LF variability of AMOC, while contributing only marginally to the time-mean and high-frequency (HF; monthly to interannual) variability of Atlantic overturning. Models can provide such low-frequency context for short observational records, but OSNAP has substantially raised the bar for studying the regional drivers of AMOC using simulations. Excessive deep convection in the Labrador Sea is a common bias in the ocean component of climate models (11-14) - a deficiency that is likely related to the absence (or inadequate parameterization) of the stratifying effects of submesoscale eddies (15) and deep overflow waters that originate in the Nordic Seas (16). High-fidelity models that exhibit a good match to observed benchmarks in terms of both deep mixing and densityspace overturning are needed to provide credible context for limited observations and thereby help to advance our understanding of LF AMOC variability. 
An unprecedented high-resolution (HR; $0.1^{\circ}$ ocean coupled to $0.25^{\circ}$ atmosphere) pre-industrial control simulation using the Community Earth System Model (CESM) Version $1.3(17,18)$ offers a novel and uniquely compelling portrait of the role of Labrador Sea processes in intrinsic LF AMOC variability. This mesoscale-eddy-resolving simulation shows dramatically improved SPNA realism compared to a low-resolution (LR: $\sim 1^{\circ}$ ocean, $\sim 1^{\circ}$ atmosphere) counterpart in the magnitude and location of winter deep convection and density-space overturning. Despite relatively low mean surface WMT in the Labrador Sea and good agreement with the OSNAP partitioning of eastern vs. western mean subpolar gyre (SPG) overturning, LF WMT variability in HR is dominated by changes in the rate of transformation in the LSW density range. LF AMOC variations at subpolar and lower latitudes can be traced to variations in the formation of deep LSW (dLSW), with Labrador Sea buoyancy forcing and deep convection implicated as essential elements in the final stage of NADW transformation and deep-water production. While LF WMT variability in the eastern SPG contributes to the preconditioning of large LSW anomalies, the simulation suggests that decadal changes in eastern SPG transformation are more a response than a driver of large LSW and associated AMOC anomalies. The picture that emerges from HR suggests that SPNA surface water mass formation (WMF), whose mean and LF variance is dominated by Labrador Sea processes, is key to understanding LF AMOC dynamics, including the spatiotemporal propagation of thermohaline circulation anomalies. These results offer valuable new perspective on the role of Labrador Sea processes in driving AMOC and suggest that OSNAP observations are not incompatible with the conceptual framework that posits a dynamically active role for the Labrador Sea in Atlantic multidecadal variability.

\section{Results}

\section{Improved Subpolar North Atlantic Realism at High Resolution}

Winter deep convection (quantified in terms of March mixed layer depth or MLD) in the Labrador Sea in LR is clearly too deep, too ubiquitous, and misplaced, with deepest mixing concentrated in the northwest of the basin where the climatological March MLD exceeds $1.5 \mathrm{~km}$ (Fig. 1A). In stark contrast, HR exhibits a good match to a recent observation-based estimate of 30 climatological March MLD (19) in terms of both the magnitude and location of Labrador Sea winter convection (Fig. 1, B and C). The improvement in HR is also evident in other regions of deep mixing, such as the Irminger and Greenland-Iceland-Norwegian (GIN) Seas, although MLD within the Irminger region (IRM; marked as region \#4 in Fig. 1A) is perhaps still excessive in HR. While the explanation for the improved representation of SPNA deep convection in HR remains unclear, it is likely that (partially resolved) high latitude ocean eddies are acting to enhance stratification by fluxing low-salinity boundary current waters into the interior Labrador Sea (15), as suggested by the swath of low MLD in the northeastern Labrador Sea adjacent to the coast of West Greenland in HR (Fig. 1B) where eddy activity is high (not shown). Low-pass filtered (LPF; see Materials and Methods) March MLD variability in LR is dominated by an expansion of convection into the southeastern Labrador Sea where Argo-based measurements indicate low mean mixing (Fig. 1D). In HR, the pattern of LF MLD variability largely coincides with the distribution of mean winter convection, although IRM and GIN here stand out as regions of maximum variance (Fig. 1E). While there is no reliable observational benchmark for LF MLD variability, it is reasonable to conclude that HR is more realistic in its simulation of both the mean and variability of winter deep convection in the SPNA. 
Direct comparison to the observed mean and HF variability of overturning across the OSNAP array lines (orange lines in Fig. 1) also reveals a significant improvement in simulation fidelity in HR compared to LR (Fig. 2; note that $\sigma_{0}$ density coordinates are used in this plot only in order to facilitate comparison with the observed data). The mean OSNAP overturning strength is too strong in both simulations, for each of the OSNAP West, East, and Total components, but the discrepancy with observed streamfunction profiles is greatly reduced in HR (cf. Fig. 2A-C, Fig. $2 \mathrm{G}-\mathrm{I})$. Although the mean maximum strength of OSNAP East overturning exceeds that of OSNAP West in LR, as in observations, the excessive winter convection in that simulation results in a much too strong and highly variable density-space overturning across OSNAP West (Fig. 2A,D). In HR, the overturning across OSNAP West still appears to be slightly too strong on average, but the observed maximum of $\sim 2.5 \mathrm{~Sv}$ is encompassed by the range of 21-month averages simulated during the 300 -year simulation, and the relative strengths of overturning across OSNAP West and East are well represented. The OSNAP East overturning in HR exhibits a larger positive bias than at OSNAP West, suggesting that if anything the simulation might overestimate the relative influence of surface transformation in the eastern SPG. The LR/HR comparisons presented above reveal a strong sensitivity to horizontal resolution in CESM, but we note that other models may show considerably less sensitivity to resolution (9). Our purpose here is not to explain the LR/HR differences, but rather to contrast the differences in fidelity of the simulations in order to highlight the suitability of HR for addressing questions about the role of the Labrador Sea in LF variability.

\section{The structure of Low Frequency AMOC Variability}

The large-scale, density-space overturning circulation in the SPNA reflects the net transformation of warm, saline, light upper limb water into cold, fresh, dense NADW. In both HR and LR, the overturning streamfunction is maximum at subpolar latitudes $\left(45^{\circ}-60^{\circ} \mathrm{N}\right)$, with LR showing stronger peak overturning than HR ( $26 \mathrm{~Sv}$ compared to $\sim 20 \mathrm{~Sv})$ but also more diabatic recirculation within the SPG (Fig. 1F,G). In both simulations, the LF variability of $\operatorname{AMOC}\left(\sigma_{2}\right)$ (see Materials and Methods) has a structure that is quite different from the mean streamfunction, with maximum variance concentrated in the dense, southward-flowing lower $\operatorname{limb}\left(\sigma_{2} \sim 37.0 \mathrm{~kg} \mathrm{~m}^{-3}\right)$. Another band of relatively high LF variance corresponds to the light, northward-flowing NAC $\left(\sigma_{2} \sim 35.0-36.5 \mathrm{~kg} \mathrm{~m}^{-3}\right)$. Recent work has focused attention on the LF coupling between the high-variance lower and upper limbs as a key source of decadal predictability in the SPNA, with variability in the abyssal ocean leading changes in the strength of upper ocean NAC flow by several years (20). The structure of AMOC variance (Fig. 1F,G) indicates that such a coupling is present in both LR and HR. We discuss below how this LF mechanism manifests in HR, but we first examine the origins of the high lower limb variance and show that it can be linked to LSW production.

Surface WMT analysis (see Materials and Methods) can reveal the regional surface drivers of ocean density-space overturning (21-32). Figure 3 compares the mean and variability of surface WMT and WMF (that is, the surface water mass formation of a given density class, computed as the convergence of WMT in density space) to the overturning streamfunction computed from the model velocity field. Surface buoyancy loss (which is dominated by ocean heat loss to the atmosphere in the SPNA; not shown) results in the transformation of AMOC upper limb waters into steadily increasing density classes as water parcels move from the central SPG into the IRM, GIN, and LAB regions (Fig. 3A) $(9,24,27,32)$. In HR, the relatively weak peak WMT rate in LAB compared to the SPG, GIN, and IRM regions (and their sum) is wholly consistent with the 
aforementioned observational studies that have stressed the dominance of the eastern SPG in the high latitude closure of AMOC (5-7). The mean magnitude of LAB WMT ( 4 Sv) is slightly less than the OSNAP West overturning circulation strength computed in $\sigma_{2}$-space (Fig. 3D), implying that the latter is partly driven by transformation outside of the Labrador Sea. It is worth noting that the peak WMT rate in the IRM region $(\sim 8 \mathrm{~Sv}$; Fig. $3 \mathrm{~A})$ is a good match to the observed estimate of $\sim 7 \mathrm{~Sv}$ obtained over the same region (7). When mean surface WMT is aggregated over all regions north of $45^{\circ} \mathrm{N}$ (a latitude chosen to represent the southern boundary of the SPG), it compares well to the mean $\operatorname{AMOC}\left(\sigma_{2}\right)$ streamfunction at $45^{\circ} \mathrm{N}$ for low densities $\left(\sigma_{2}<36.2 \mathrm{~kg}\right.$ $\mathrm{m}^{-3}$ ), but there are large discrepancies at higher densities (Fig. 3C). This mismatch, likely attributable to the effects of interior diapycnal mixing (24), suggests that identifying a relation between WMT and overturning strength may not be as straightforward as comparing their respective maxima as is commonly done. The mean WMF curves reveal net annual formation of subpolar mode water (SPMW; $\left.\sigma_{2} \sim 36.4 \mathrm{~kg} \mathrm{~m}^{-3}\right)$ and LSW $\left(\sigma_{2} \sim 37.1 \mathrm{~kg} \mathrm{~m}^{-3}\right)$ in the SPNA, with the latter clearly the primary end product of SPNA surface transformation (Fig. 3B). The northern SPG and IRM regions contribute to LSW formation, presumably in areas of deep winter mixing surrounding the southern tip of Greenland (Fig. 1B), but the interior LAB region dominates mean LSW production (Fig. 3B).

The LF variabilities of WMT and WMF in HR exhibit very strong peaks in the LSW density range, with local buoyancy forcing in the interior Labrador Sea implicated as a key driver (Fig. 3E,F). The WMF variance peak occurs at densities slightly greater than the corresponding peak in mean WMF (cf. Figs. 3B,F), implying that the rate of formation of dLSW, in particular, is highly variable on decadal to multidecadal timescales. The WMT variance peak coincides with the lower limb overturning variance peak highlighted above (Fig. 1G), particularly at subpolar latitudes near the southern edge of the Labrador Sea (e.g., at $55^{\circ} \mathrm{N}$, blue curve in Fig. $3 \mathrm{G}$ ). At lower latitudes (e.g., at $45^{\circ} \mathrm{N}$, red curve in Fig. $3 \mathrm{G}$ ) this deep variance maximum is still strong, but weaker and more diffuse, suggestive of mixing with lighter waters as LSW anomalies propagate southwards. The LF variance across OSNAP East also exhibits the double peak structure seen in the latitudinal streamfunction (i.e., Figs. 1G, 3G), with lower limb variance roughly matching that seen at OSNAP West (Fig. 3H). Here again, the lower limb variance is interpreted as reflecting LF changes in LSW surface transformation and formation occurring along the swath of high MLD variability extending from the interior Labrador Sea to the southeast coast of Greenland (Fig. 1E). The same analysis performed in LR shows qualitatively similar results, but with greatly exaggerated mean and variance associated with Labrador Sea surface WMT (fig. S1). To summarize, surface WMT analysis of HR implies an active role for Labrador Sea processes in driving LF AMOC lower limb variability - a dominance that is far larger than would be expected given the relatively weak OSNAP West overturning and the Labrador Sea's small contribution to the net surface transformation that sustains the time-mean overturning in the North Atlantic.

\section{The Causal Linkages between Surface Transformation and AMOC}

The temporal relationship between LF variations in SPNA surface WMT and AMOC is first examined in Figure 4 which displays the full structure of detrended anomalies in density-time space from HR. The net surface WMT over all SPNA regions north of $45^{\circ} \mathrm{N}$ (Fig. 4B) is decomposed into regions lying to the east (Fig. 4C) and to the west (Fig. 4D) of Cape Farewell (the southernmost tip of Greenland). Multidecadal AMOC anomalies at $45^{\circ} \mathrm{N}$ are characterized by an upward tilt in density space, indicating that LF AMOC signals originate in the abyssal, southward-flowing lower limb (Fig. 4A). Variations in the formation rate of dLSW associated 
with Labrador Sea surface buoyancy forcing clearly precede the variations in AMOC lower limb $\left(\sigma_{2} \sim 37.0 \mathrm{~kg} \mathrm{~m}^{-3}\right)$ transport (Fig. 4A). The deep transport fluctuations lead by several years samesigned anomalies in net overturning strength (corresponding to $\mathrm{AMOC}\left(\sigma_{2}\right)_{\max }$ and associated with a time-varying location in density space, $\sigma_{\max }$, indicated by dotted line in Fig. 4A) and upper limb (NAC; $\sigma_{2} \sim 35.0-35.5 \mathrm{~kg} \mathrm{~m}^{-3}$ ) transport (Fig. 4A). For example, the positive NAC anomaly at year 405 appears to be a response to a large dLSW formation anomaly around year 395 (Fig. 4A). The lagged relationship between lower and upper limb transports has been ascribed to the interior propagation of dLSW thickness anomalies followed by the development of steric sea surface height anomalies that alter the near surface flow (20). This mechanism will be further elucidated below. SPNA WMT anomalies are seen to emanate from the AMOC upper limb signals. For example, the positive NAC anomaly at year 405 instigates a positive WMT anomaly that propagates from low to high density through the full range of SPNA surface density space (Fig. 4B). The density-space propagation of coherent, decadal WMT anomalies occurs primarily in the eastern SPG (Fig. 4C) and is likely related to upper ocean temperature and salinity anomalies that modulate the strength of surface transformation as they propagate around the gyre towards higher density regions. The detailed mechanism that explains this WMT propagation, and the degree to which it is associated with anomalous isopycnal outcrop area or air-sea buoyancy flux or both, remains unclear. The finding that surface WMT in the eastern SPG is a lagged response to LF variations in AMOC lower limb transport is consistent with previous work (32), but novel mechanistic insight is added here by clarifying the source of the lower limb variability and its time-delayed influence on eastern WMT via the NAC.

Previous work suggests that the LF dLSW formation anomalies are likely related to variations in North Atlantic Oscillation (NAO) forcing (e.g., 20), but a detailed explanation of their origins in HR is beyond the scope of this study. The dLSW formation anomalies are clearly highly correlated with SPNA WMT anomalies in the LSW density class (Fig. 4B), as expected given that dLSW formation represents the high-density end product of surface WMT (note that the slight lead of dLSW anomalies is related to the fact that it is the density-space convergence of WMT). Strong WMT anomalies at high densities $\left(\sigma_{2}>37.0 \mathrm{~kg} \mathrm{~m}^{-3}\right)$ occur mostly within the Labrador Sea region (Fig. 4D; the contribution from SPG_west is small, not shown) but with nontrivial contribution from eastern regions (Fig. 4C). Figure 4 suggests that, in addition to local surface buoyancy forcing, preconditioning of surface waters contributes to anomalous WMT in the LSW density range. For example, the negative dLSW formation anomaly at year 450 is preceded by a propagating, negative WMT anomaly in the eastern SPG (Fig. 4C), finally culminating in a large negative WMT anomaly at high density (Fig. 4B) that has strongest expression in the LAB region (Fig. 4D). The implication is that SPNA surface WMT and overturning circulation at the southern boundary of the SPG $\left(\sim 45^{\circ} \mathrm{N}\right)$ are coupled on multidecadal timescales in a gyre mode that has a periodicity of roughly 20 years (further elucidated below) in line with previous work (33), with the lower latitude AMOC both driving, and responding to, LF variations in higher latitude WMT.

The mean causal relationships between AMOC and regional WMT are summarized in Figure 5 which shows lag composite anomalies associated with strong overturning at $45^{\circ} \mathrm{N}$. The time series of detrended, LF AMOC strength at $45^{\circ} \mathrm{N}$ (Fig. 5A) explains more than $90 \%$ of the variance in LF meridional ocean heat transport across that latitude ( $\mathrm{r}=0.96$; not shown). Large, positive $\mathrm{AMOC}_{\max }$ anomalies (exceeding 1 standard deviation; Fig. 5A) are consistently associated with a spin up of the abyssal transport beginning $\sim 5$ years prior, while the peak in upper limb transport lags $\mathrm{AMOC}_{\max }$ by a few years (Fig. 5B). The lower limb spin up that leads 
$\mathrm{AMOC}_{\max }$ is linked to increased WMT at surface densities greater than $36.25 \mathrm{~kg} \mathrm{~m}^{-3}$ (a density threshold that corresponds to the peak rate of WMT in the Irminger Sea), and greatly enhanced WMT in the LSW density range (Fig. 5C). Positive WMT anomalies at relatively high densities in the eastern SPG precede $\mathrm{AMOC}_{\max }$ by as much as a decade (Fig. 5D), implying a role for preconditioning. However, there is a notable gap in the transmission of the WMT signal as it approaches $\sigma_{2} \sim 37.0 \mathrm{~kg} \mathrm{~m}^{-3}$ and the largest WMT anomalies at negative lag occur simultaneously, suggesting a common anomalous air-sea flux forcing. The LAB region clearly stands out as the proximate driver of abyssal AMOC, with large amplitude WMT anomalies in the LSW range (Fig. 5E) coinciding with large WMF anomalies in the dLSW range (Fig. 5F). The composite analysis shows that, on average, WMT anomalies in the LSW density range drive AMOC, whereas WMT anomalies at lower densities in the SPNA are largely a response as they lag changes in overturning strength at $45^{\circ} \mathrm{N}$ and are coincident with the time-delayed increase in NAC transport. The roughly 20 year timescale mentioned above can be understood as having two parts: 1) a 5 year delay between dLSW formation and NAC spin up at $45^{\circ} \mathrm{N}$ (Fig. $5 \mathrm{~A}, \mathrm{~F}$ ), and 2) a 15 year propagation of WMT anomalies from low to high density (Fig. 5C). Composites for large, negative AMOC anomalies lead to similar conclusions, albeit with WMT in the eastern SPG playing a larger role in preconditioning, and the LAB region showing less dominance, than for positive AMOC anomalies (fig. S2).

\section{Coupling between AMOC lower and upper limbs}

The WMT analysis presented above provides a "top-down" perspective on LF AMOC variability that highlights the driving role of anomalous surface buoyancy forcing at the high-density tail end of NADW formation in the basins around Greenland where LSW is formed. Figure 6 illustrates the "bottom-up" dynamics involved in the subsequent coupling between AMOC lower and upper limb transports. Starting roughly 6 years prior to positive $A M O C_{\max }$ at $45^{\circ} \mathrm{N}$, there is enhanced winter deep convection in the interior Labrador Sea (Fig. 6B1) accompanied by a stronger transport of high density LSW-precursor waters near the Greenland coast at $60^{\circ} \mathrm{N}$ (Fig. 6A1). At this stage, the deep ocean in the SPNA is characterized by an anomalously thin dLSW layer (Fig. 6C1), while the surface ocean in the SPNA exhibits anomalously elevated (depressed) sea surface height (SSH) in the west (east) (Fig. 6D1). The latter is consistent with weak zonal mean NAC flow (Fig. 6A1). Winter convection grows more active in Labrador Sea in the years leading up to $\mathrm{AMOC}_{\max }$, and the enhanced deep mixing extends into the western Irminger Sea (Fig. 6B2,B3), consistent with the timing of anomalous regional WMT in the LSW class (Fig. $5 \mathrm{D}, \mathrm{E})$. There is a corresponding growth of large, positive dLSW layer thickness anomalies, particularly in the convection regions but also extending southward along the western boundary of the SPNA and to the east of the Grand Banks of Newfoundland (Fig. 6C2-C5). Positive abyssal thickness anomalies (of order $100 \mathrm{~m}$ in the dLSW layer) contribute to negative SSH anomalies (of order $1 \mathrm{~cm}$ ) in the western SPNA and Irminger Sea (Fig. 6D2-D6). As the AMOC deep limb transport increase spreads southward, there is a concomitant increase in NAC transport that spreads northward (Fig. 6A1-A8). The northward propagation of NAC strength relates to the increase in SSH gradient with time at latitudes north of about $40^{\circ} \mathrm{N}$ induced by the dual effects of western depressed SSH (associated with abyssal thickness anomalies) and eastern elevated SSH (associated with AMOC and heat transport spin up at lower latitudes and associated heat transport convergence in the upper ocean). At high latitudes $\left(\sim 55^{\circ} \mathrm{N}\right)$, the time delay between the spin up of the lower and upper limbs spans some 12-14 years (Fig. 6A1-A8). This delay has been

\section{Discussion}


The realism of SPNA deep convection and overturning across the OSNAP array in a multicentury, mesoscale eddy resolving, coupled control simulation makes it a uniquely powerful dataset for studying the origins of AMOC intrinsic low-frequency variability, elucidating the relative roles of diapycnal transformation in the eastern vs. western subpolar gyre, and providing long timescale context for interpreting recent, short observational records. The LF variability of density-space overturning at $45^{\circ} \mathrm{N}$, which accounts for almost all the LF variance in ocean heat transport into the SPNA, is dominated by large amplitude fluctuations in southward-flowing lower limb transport. Regional surface WMT analysis reveals a corresponding dominance of LF WMT variance at the high-density end of the SPNA water mass distribution. While the mean transformation of warm, light NAC water into cold, dense NADW takes place predominately in the eastern SPG and Irminger Sea with a peak transformation rate of about $16 \mathrm{~Sv}$ at mid-densities $\left(\sigma_{2} \sim 36.25 \mathrm{~kg} \mathrm{~m}^{-3}\right)$, in line with recent observational findings $(3,5-7)$, the multidecadal standard deviation of WMT in the LSW range $\left(\sigma_{2} \sim 37.0 \mathrm{~kg} \mathrm{~m}^{-3}\right)$ is more than twice as large as that at lower density. Most of this LF variability in high-density diapycnal transformation takes place in the interior Labrador Sea, but also in adjacent regions around the southern tip of Greenland where winter convection is deep and highly variable. The implication is that the tail wags the dog in the North Atlantic on multidecadal timescales-while the Labrador Sea contributes only marginally to the net water mass transformation required to sustain the time mean Atlantic thermohaline circulation, it plays an outsized role in driving the LF variability of AMOC. These findings offer a novel conceptual framework for reconciling the observation-based and modelbased perspectives on the subpolar origins of Atlantic overturning circulation.

The importance of the Labrador Sea (and more generally, of SPNA deep convection regions) highlighted by WMT diagnostics suggests that surface water mass formation is a critical element in LF AMOC dynamics, not just transformation. The Labrador Sea stands out as the primary location of deep-water formation which is the end result of the net densification of surface waters in the SPNA and the high-density convergence of that diapycnal transformation. The LF variability of both WMT and WMF is concentrated in the LSW density range, suggesting a positive feedback whereby anomalous WMT at the tail end of transformation leads to anomalous WMF (and deep convection) that leads to more WMT in the same LSW density range. Large multidecadal AMOC fluctuations in HR are consistently associated with dLSW formation anomalies, and the resulting deep layer thickness anomalies drive upper limb transport anomalies by inducing large-scale SSH gradients. It seems likely that LSW formation and abyssal layer thickness are essential components of multidecadal ocean memory (20) and that their prominence in AMOC dynamics increases with timescale. We speculate that the dominant period of intrinsic AMOC variability in climate models may be related to the amplitude of LSW formation variability, with larger abyssal thickness anomalies tending to produce more persistent AMOC responses. The comparison of LR and HR is consistent with this idea. The spectral peaks of AMOC variability in LR and HR occur at roughly 50-year and 20-year periods respectively (17), which may reflect the much greater (and as we have argued, less realistic) LSW formation variability in LR compared to HR (cf. Figs. 3F, S1F). The multi-model analysis required to fully test this hypothesis is beyond the scope of the present study.

While this study emphasizes the outsized role of the Labrador Sea and associated variations in the densest class of NADW produced south of the Greenland-Scotland Ridge in setting the pace of LF AMOC variability, a complete understanding of AMOC variability requires a holistic view of all the diapycnal transformation processes that take place in the high latitude North Atlantic, including the effects of interior mixing. We argue that Labrador Sea processes are nontrivial and 
indeed crucial for understanding LF AMOC mechanisms, but at the same time acknowledge that east vs. west reductionism is almost certainly too simplistic. Our analysis indicates that AMOC anomalies are usually preceded by anomalous WMT in the eastern SPG, which primes the pump for anomalous LSW formation and/or contributes to a direct driving of the AMOC lower limb at densities only slightly greater than $\sigma_{\max }$ (likely, through mixing with denser LSW). WMT precursor anomalies at short lead times appear to be quite large-scale (nearly simultaneous and spanning multiple regions and surface density classes) which suggests a common flux forcing (e.g., NAO) and makes it quite challenging to definitively and quantitatively decompose the regional surface origins of AMOC variability. Our inference that the Labrador Sea is more active than suggested by earlier work (9) is based on the following lines of evidence: (1) LF WMT variability is by far largest in the LSW density range and is dominated by interior Labrador Sea buoyancy forcing, (2) AMOC $\left(\sigma_{2}\right)$ exhibits maximum LF variability near the LSW density range and its autocorrelation shows an "upward" propagation of signal, (3) large LF AMOC anomalies are consistently preceded by WMT anomalies that have largest amplitude in the LSW density range and in the Labrador Sea region, (4) LF WMT anomalies in the eastern SPNA are largest when they lag AMOC, and (5) anomalous LSW formation (largely occurring within the Labrador Sea) provides a basis for understanding the longevity of AMOC anomalies as well as the delayed response of upper limb transport. These results build on previous studies that have examined the links between WMT and density-space AMOC in long model simulations (32), but they provide a clearer picture of the key causal relationships by considering the full density-space dependence of LF signals.

The strength of the conclusions that can be drawn from analysis of a single model simulation is limited, but a single high-fidelity simulation does suffice to demonstrate that OSNAP observations are not necessarily incompatible with the hypothesis that the Labrador Sea is dynamically active on subdecadal timescales. Further work is needed to demonstrate the robustness across models of the mechanisms described herein, but with the caveat that models must demonstrate reasonable agreement with existing observations (i.e., must not exhibit excessive Labrador Sea diapycnal transformation) in order to provide persuasive context. This restriction could severely limit the number of qualifying model simulations. The LR counterpart to HR does not meet this standard, and although its LF AMOC and WMT co-variability is similar in most respects to that of HR, the role of Labrador Sea processes in that simulation is almost certainly exaggerated. Previous work suggests that high horizontal model resolution is not necessarily required for good comparison with OSNAP measurements (9), and neither does it guarantee a close match, as evidenced by the fact that the observed OSNAP overturning mean and variability is not fully encompassed by HR. The treatment of small-scale Nordic Sea overflow dynamics, which are neither parameterized nor fully resolved in HR, is likely a factor that influences Labrador Sea convective activity (16). The role of Labrador Sea transformation in HR may well be overestimated due to deficient deep stratification associated with Denmark Strait Overflow Water.

Developing a deeper understanding of the mechanisms of AMOC variability clearly requires a dual approach of observing and modeling with each informing the other. Recent advances in the AMOC observing system exemplified by the OSNAP array are coincident with an increasing capacity to perform climate scale global simulations at eddy-resolving ocean resolution. This study demonstrates the promise of a new generation of high-fidelity coupled climate models that are capable of explicitly resolving most of the spatial and temporal scales that are believed to be important for climate phenomena such as AMOC. The results suggest that the Labrador Sea is 
not as inconsequential as implied by the recent literature, and it may have a relevance that increases with timescale. Ultimately, a much longer observational record is needed to determine if this is true, but in the meantime, there is hope that ongoing model development and resolution enhancement will lead to more reliable and convergent understanding of AMOC mechanisms.

\section{References and Notes}

1. R. Zhang, R. Sutton, G. Danabasoglu, Y.-O. Kwon, R. Marsh, S. G. Yeager, D. E. Amrhein, C. M. Little: A review of the role of the Atlantic Meridional Overturning Circulation in Atlantic Multidecadal Variability and associated climate impacts. Reviews of Geophysics $\mathbf{5 7}$, 316-375 (2019). doi:10.1029/2019RG000644

2. M. W. Buckley, J. Marshall: Observations, inferences, and mechanisms of the Atlantic Meridional Overturning Circulation: A Review. Reviews of Geophysics 54, 5-63 (2016). doi:10.1002/2015RG000493

3. M. S. Lozier, F. Li, S. Bacon, F. Bahr, A. S. Bower, S. A. Cunningham, M. F. de Jong, L. de Steur, B. DeYoung, J. Fischer, S. F. Gary, B. J. W. Greenan, N. P. Holliday, A. Houk, L. Houpert, M. E. Inall, W. E. Johns, H. L. Johnson, C. Johnson, J. Karstensen, G. Koman, I. A. Le Bras, X. Lin, N. Mackay, D. P. Marshall, H. Mercier, M. Oltmanns, R. S. Pickart, A. L. Ramsey, D. Rayner, F. Straneo, V. Thierry, D. J. Torres, R. G. Williams, C. Wilson, J. Yang, I. Yashayaev, J. Zhao: A sea change in our view of overturning in the subpolar North Atlantic. Science 363, 516-521 (2019). doi:10.1126/science.aau6592

4. R. S. Pickart, M. A. Spall: Impact of Labrador Sea Convection on the North Atlantic Meridional Overturning Circulation. J. Phys. Oceanogr. 37, 2207-2227 (2007). doi:10.1175/JPO3178.1

5. L. Chafik, T. Rossby: Volume, Heat, and Freshwater Divergences in the Subpolar North Atlantic Suggest the Nordic Seas as Key to the State of the Meridional Overturning Circulation. Geophys. Res. Lett. 46, 4799-4808 (2019). doi:10.1029/2019GL082110

6. D. Desbruyères, H. Mercier, G. Maze, N. Daniault: Surface predictor of overturning circulation and heat content change in the subpolar North Atlantic. Ocean Sci. 15, 809-817 (2019). doi:10.5194/os-15-809-2019

7. T. Petit, M. S. Lozier, S. A. Josey, S. A. Cunningham: Atlantic Deep Water Formation Occurs Primarily in the Iceland Basin and Irminger Sea by Local Buoyancy Forcing. Geophys. Res. Lett. 47, e2020GL091028 (2020). doi:10.1029/2020GL091028

8. P. Ortega, J. I. Robson, M. Menary, R. T. Sutton, A. Blaker, A. Germe, J. J.-M. Hirschi, B. Sinha, L. Hermanson, S. Yeager: Labrador Sea sub-surface density as a precursor of multidecadal variability in the North Atlantic: a multi-model study. Earth Syst. Dynam. [in press] (2021). doi:10.5194/esd-2020-83

9. M. B. Menary, L. C. Jackson, M. S. Lozier: Reconciling the Relationship Between the AMOC and Labrador Sea in OSNAP Observations and Climate Models. Geophys. Res. Lett. 47, e2020GL089793 (2020). doi:10.1029/2020GL089793

10. G. A. MacGilchrist, H. L. Johnson, D. P. Marshall, C. Lique, M. Thomas, L. C. Jackson, R. A. Wood: Locations and Mechanisms of Ocean Ventilation in the High-Latitude North 
Atlantic in an Eddy-Permitting Ocean Model. J. Clim. 33, 10113-10131 (2020). doi:10.1175/JCLI-D-20-0191.1

11. G. Danabasoglu, S. G. Yeager, D. Bailey, E. Behrens, M. Bentsen, D. Bi, A. Biastoch, C. Böning, A. Bozec, V. M. Canuto, C. Cassou, E. Chassignet, A. C. Coward, S. Danilov, N. Diansky, H. Drange, R. Farneti, E. Fernandez, P. G. Fogli, G. Forget, Y. Fujii, S. M. Griffies, A. Gusev, P. Heimbach, A. Howard, T. Jung, M. Kelley, W. G. Large, A. Leboissetier, J. Lu, G. Madec, S. J. Marsland, S. Masina, A. Navarra, A. J. G. Nurser, A. Pirani, D. S. y Mélia, B. L. Samuels, M. Scheinert, D. Sidorenko, A.-M. Treguier, H. Tsujino, P. Uotila, S. Valcke, A. Voldoire, Q. Wang: North Atlantic simulations in Coordinated Ocean-ice Reference Experiments phase II (CORE-II). Part I: Mean states. Ocean Modelling 73, 76-107 (2014). doi:10.1016/j.ocemod.2013.10.005

12. F. Li, M. S. Lozier, G. Danabasoglu, N. P. Holliday, Y.-O. Kwon, A. Romanou, S. G. Yeager, R. Zhang: Local and Downstream Relationships between Labrador Sea Water Volume and North Atlantic Meridional Overturning Circulation Variability, J. Climate 32, 3883-3898 (2019). doi:10.1175/JCLI-D-18-0735.1

13. C. Heuzé: North Atlantic deep water formation and AMOC in CMIP5 models, Ocean Sci. 13, 609-622 (2017). doi: 10.5194/os-13-609-2017

14. M. J. Roberts, L. C. Jackson, C. D. Roberts, V. Meccia, D. Docquier, T. Koenigk, P. Ortega, E. Moreno-Chamarro, A. Bellucci, A. Coward, S. Drijfhout, E. Exarchou, O. Gutjahr, H. Hewitt, D. Iovino, K. Lohmann, D. Putrasahan, R. Schiemann, J. Seddon, L. Terray, X. Xu, Q. Zhang, P. Chang, S. G. Yeager, F. S. Castruccio, S. Zhang, L. Wu: Sensitivity of the Atlantic Meridional Overturning Circulation to model resolution in CMIP6 HighResMIP simulations and implications for future changes. Journal of Advances in Modeling Earth Systems 12, e2019MS002014 (2020). doi:10.1029/2019MS002014

15. F. Tagklis, A. Bracco, T. Ito, R. M. Castelao: Submesoscale modulation of deep water formation in the Labrador Sea. Sci. Rep. 10, 17489 (2020). doi: 10.1038/s41598-020-74345$\mathrm{W}$

16. S. Yeager, G. Danabasoglu: Sensitivity of Atlantic Meridional Overturning Circulation Variability to Parameterized Nordic Sea Overflows in CCSM4. J. Clim. 25, 2077-2103 (2012). doi:10.1175/JCLI-D-11-00149.1

17. S. Zhang, H. Fu, L. Wu, Y. Li, H. Wang, Y. Zeng, X. Duan,W. Wan, L. Wang, Y. Zhuang, H. Meng, K. Xu, P. Xu, L. Gan, Z. Liu, S. Wu, Y. Chen, H. Yu, S. Shi, L. Wang, S. Xu, W. Xue, W. Liu, Q. Guo, J. Zhang, G. Zhu, Y. Tu, J. Edwards, A. Baker, J. Yong, M. Yuan, Y. Yu, Q. Zhang, Z. Liu, M. Li, D. Jia, G. Yang, Z. Wei, J. Pan, P. Chang, G. Danabasoglu, S. Yeager, N. Rosenbloom, Y. Guo: Optimizing high-resolution Community Earth System Model on a heterogeneous many-core supercomputing platform. Geosci. Model Dev., 13, 4809-4829 (2020). doi:10.5194/gmd-13-4809-2020

18. P. Chang, S. Zhang, G. Danabasoglu, S. G. Yeager, H. Fu, H. Wang, F. S. Castruccio, Y. Chen, J. Edwards, D. Fu, Y. Jia, L. C. Laurindo, X. Liu, N. Rosenbloom, R. J. Small, G. Xu, Y. Zeng, Q. Zhang, J. Bacmeister, D. A. Bailey, X. Duan, A. K. DuVivier, D. Li, Y. Li, R. Neale, A. Stössel, L. Wang, Y. Zhuang, A. Baker, S. Bates, J. Dennis, X. Diao, B. Gan, A. Gopal, D. Jia, Z. Jing, X. Ma, R. Saravanan, W. G. Strand, J. Tao, H. Yang, X. Wang, Z. Wei, L. Wu: An Unprecedented Set of High-Resolution Earth System Simulations for Understanding Multiscale Interactions in Climate Variability and Change. Journal of 
Advances in Modeling Earth Systems 12, e2020MS002298 (2020). doi:10.1029/2020MS002298

19. J. Holte, L. D. Talley, J. Gilson, D. Roemmich: An Argo mixed layer climatology and database. Geophys. Res. Lett. 44, 5618-5626 (2017). doi:10.1002/2017GL073426

20. S. G. Yeager: The abyssal origins of North Atlantic decadal predictability. Clim. Dyn. 55, 2253-2271 (2020). doi:10.1007/s00382-020-05382-4

21. G. Walin: On the relation between sea-surface heat flow and thermal circulation in the ocean. Tellus 34, 187-195 (1982).

22. K. G. Speer and E. Tziperman: Rates of water mass formation in the North Atlantic Ocean. $J$. Phys. Oceanogr. 22, 93-104 (1992).

23. A. J. G. Nurser, R. Marsh, R. G. Williams: Diagnosing water mass formation from air-sea fluxes and surface mixing. J. Phys. Oceanogr. 29, 1468-1487 (1999).

24. X. Xu, P. B. Rhines, E. P. Chassignet: On Mapping the Diapycnal Water Mass Transformation of the Upper North Atlantic Ocean. J. Phys. Oceanogr. 48, 2233-2258 (2018). doi: 10.1175/JPO-D-17-0223.1

25. R. Marsh: Recent Variability of the North Atlantic Thermohaline Circulation Inferred from Surface Heat and Freshwater Fluxes. J. Clim. 13, 3239-3260 (2000).

26. J. P. Grist, S. A. Josey, R. Marsh, Y.-O. Kwon, R. J. Bingham, A. T. Blaker: The SurfaceForced Overturning of the North Atlantic: Estimates from Modern Era Atmospheric Reanalysis Datasets. J. Clim. 27, 3596-3618 (2014). doi:10.1175/JCLI-D-13-00070.1

27. E. Brambilla, L. D. Talley, P. E. Robbins: Subpolar Mode Water in the northeastern Atlantic: 2. Origin and transformation, J. Geophys. Res. 113, C04026 (2008). doi:10.1029/2006JC004063

28. S. K. Gulev, B. Barnier, J.-M. Molines, T. Penduff, J. Chanut: Impact of spatial resolution on simulated surface water mass transformations in the Atlantic. Ocean Model. 19, 138-160 (2007). doi: 10.1016/j.ocemod.2007.07.004

29. J. P. Grist, R. Marsh, S. A. Josey: On the Relationship between the North Atlantic Meridional Overturning Circulation and the Surface-Forced Overturning Streamfunction. J. Clim. 22, 4989-5002 (2009). doi:10.1175/2009JCLI2574.1

30. S. A. Josey, J. P. Grist, R. Marsh: Estimates of meridional overturning circulation variability in the North Atlantic from surface density flux fields. J. Geophys. Res. 114, C09022 (2009). doi: $10.1029 / 2008 \mathrm{JC} 005230$

31. J. P. Grist, S. A. Josey, R. Marsh: Surface estimates of the Atlantic overturning in density space in an eddy-permitting ocean model. J. Geophys. Res. 117, C06012 (2012). doi:10.1029/2011JC007752

32. H. R. Langehaug, P. B. Rhines, T. Eldevik, J. Mignot, K. Lohmann: Water mass transformation and the North Atlantic Current in three multicentury climate model simulations. J. Geophys. Res. 117, C11001 (2012). doi:10.1029/2012JC008021

33. M. B. Menary, D. L. R. Hodson, J. I. Robson, R. T. Sutton, R. A. Wood: A Mechanism of Internal Decadal Atlantic Ocean Variability in a High-Resolution Coupled Climate Model. $J$. Clim. 28, 7764-7785 (2015). doi:10.1175/JCLI-D-15-0106.1 
34. W. G. Large, G. Danabasoglu, S. C. Doney, J. C. McWilliams: Sensitivity to Surface Forcing and Boundary Layer Mixing in a Global Ocean Model: Annual-Mean Climatology. J. Phys. Oceanogr. 27, 2418-2447 (1997).

35. G. A. Meehl, D. Yang, J. M. Arblaster, S. C. Bates, N. Rosenbloom, R. Neale, J. Bacmeister, P. H. Lauritzen, F. Bryan, J. Small, J. Truesdale, C. Hannay, C. Shields, W. G. Strand, J. Dennis, G. Danabasoglu: Effects of model resolution, physics, and coupling on Southern Hemisphere storm tracks in CESM1. 3. Geophys. Res. Lett. 46, 12,408-12,416 (2019). doi:10.1029/2019GL084057

Acknowledgments: The National Center for Atmospheric Research (NCAR) is a major facility sponsored by the National Science Foundation (NSF) under Cooperative Agreement 1852977. The CESM project is supported primarily by the NSF. All computing and data storage resources were provided by the International Laboratory for High Resolution Earth System Prediction (iHESP), a trilateral partnership between Qingdao Pilot National Laboratory for Marine Science and Technology (QNLM), Texas A\&M University (TAMU), and NCAR.

Funding: Funding for this work was provided by the International Laboratory for High Resolution Earth System Prediction (iHESP) and by the NSF via its support of NCAR.

\section{Author contributions:}

Conceptualization: $\mathrm{SY}$

Investigation: SY, FC, PC, GD, JS, HW, SZ

Visualization: SY

Funding acquisition: PC, GD, LW

Project administration: SY, PC, GD, SZ, LW

Software: SY, EM

Supervision: SY, PC, GD, SZ

Writing - original draft: SY

Writing - review \& editing: SY, PC, GD, EM, JS

Competing interests: Authors declare that they have no competing interests.

Data and materials availability: The model data used in this paper are available from the iHESP data portal (https://ihesp.tamu.edu/products/ihesp-products/data-

release/PI_control/index.html) and the QNLM data portal (http://ihesp.qnlm.ac). The CESM code used for the simulations is available at ZENODO via

https://doi.org/10.5281/zenodo.3637771. Argo-based mixed layer depth data were obtained from http://mixedlayer.ucsd.edu/. OSNAP overturning data are available at https://www.osnap.org/. Code used to generate plots is available upon request.

\section{Supplementary Materials}

Materials and Methods

Figs. S1 to S2

\section{Figure Legends}


Fig. 1. Mean and LF Variability of March Deep Convection and AMOC. Climatological mean (average over simulation years 200-500) March mixed layer depth (MLD) from (A) LR and (B) HR. (C) Argo-based MLD climatology using a density threshold method (18). LF March MLD standard deviation from (D) LR and (E) HR. Climatological mean (contoured at $2 \mathrm{~Sv}$ intervals) and LF standard deviation (color fill) of $\operatorname{AMOC}\left(\sigma_{2}\right)$ from $(\mathbf{F}) \mathrm{LR}$ and $(\mathbf{G}) \mathrm{HR}$. Orange lines in (A, B) show the locations of the OSNAP West and East arrays interpolated onto the model grid. Orange and yellow lines demarcate WMT regions north of $45^{\circ} \mathrm{N}$ referred to in the text as follows: 1. Labrador Sea (LAB), 2. Western subpolar gyre (SPG-west), 3. Eastern subpolar gyre (SPG-east), 4. Irminger Sea (IRM), 5. Greenland-Iceland-Norwegian Seas (GIN), and 6. Arctic Ocean (ARC). All fields were detrended and low-pass filtered (see Materials and Methods) prior to computation of standard deviation.

Fig. 2. Comparison to OSNAP overturning observations. (A-C) 21-month mean overturning across OSNAP West, OSNAP East, and OSNAP Total from LR. (D-F) 21-month standard deviation of overturning across OSNAP West, OSNAP East, and OSNAP Total from LR. (G-L) Same as (A-F) but from HR. In each panel, OSNAP observations are shown in red, black curves show the model long-term mean statistics (corresponding to simulation years 200-500), and grey shading gives the $\mathrm{min} / \mathrm{max}$ range of the statistic computed over rolling 21 -month windows.

Fig. 3. Mean and Low-Frequency Variability of WMT, WMF, and MOC. Climatological mean (average over simulation years 200-500) (A) WMT, (B) WMF, (C) WMT compared to overturning at $45^{\circ} \mathrm{N}$ and $55^{\circ} \mathrm{N}$, and (D) overturning across OSNAP array lines. (E-H) LF standard deviation of overturning variables plotted in panels (A-D). All fields are from the HR simulation (see Fig. S1 for corresponding LR plot). The approximate density range of model Labrador Sea Water (LSW) is shown in panel (B), with the denser half of the range (in black) indicating deep LSW (dLSW). All fields were detrended and low-pass filtered (see Materials and Methods) prior to computation of standard deviation.

Fig. 4. Multidecadal Cycles of LSW Formation, Thermohaline Circulation, and Surface Transformation from HR. LF anomalies from years 200-500 of the HR simulation of: (A) $\operatorname{AMOC}\left(\sigma_{2}\right)$ at $45^{\circ} \mathrm{N},(\mathbf{B}) \mathrm{WMT}$ over all regions (north of $\left.45^{\circ} \mathrm{N}\right),(\mathbf{C}) \mathrm{WMT}$ over the Irminger, GIN, and SPG-east regions, (D) WMT over the Labrador and SPG-west regions. Bar contour at "dLSW" label on y-axis of each panel shows anomalous surface WMF of dLSW within the LAB region (note that it is the same in each panel). The dLSW formation timeseries is a sum over the $\sigma_{2}$ dimension (refer to Fig. 3B for the corresponding density range) and is plotted as a contour bar at the bottom of each panel to facilitate comparison with streamfunction anomalies. Dotted lines show the density corresponding to the time-varying maxima of the respective LF streamfunctions. All fields were detrended and low-pass filtered (see Materials and Methods).

40 Fig. 5. WMT and WMF anomalies associated with strong overturning at $45^{\circ} \mathrm{N}$. From $\mathrm{HR}$, lag composite anomalies corresponding to large positive $\operatorname{AMOC}\left(\sigma_{2}\right)$ strength anomalies. (A) Time series of detrended, $\mathrm{LF} \operatorname{AMOC}\left(\sigma_{2}\right)_{\max }$ at $45^{\circ} \mathrm{N}$ with red fill indicating time periods used in composite $(>+1 \sigma)$. Composites of: $(\mathbf{B})$ AMOC $\left(\sigma_{2}\right)$ at $45^{\circ} \mathrm{N} ;(\mathbf{C})$ Total WMT north of $45^{\circ} \mathrm{N}$; (D) WMT in the eastern SPNA (combined IRM+GIN+SPG-east region); (E) WMT in the Labrador Sea (LAB region); (F) Total WMF north of $45^{\circ} \mathrm{N}$. Dashed black lines in panels (A, C-E) give the density where the respective mean overturning streamfunctions are maximum. $\operatorname{AMOC}\left(\sigma_{2}\right)_{\max }$ 
lags for negative values and leads for positive values along the $\mathrm{x}$-axis (i.e., time increases from left to right). All fields were detrended and low-pass filtered (see Materials and Methods).

Fig. 6. SPNA anomalies associated with strong $\operatorname{AMOC}\left(\sigma_{2}\right)$ at $45^{\circ}$ N. From HR, lag composite anomalies corresponding to $\operatorname{AMOC}\left(\sigma_{2}\right)$ strength at $45^{\circ} \mathrm{N}$ (computed as the maximum in density space) exceeding +1 standard deviation (refer to time series shown in Figure 5A). (A) $\operatorname{AMOC}\left(\sigma_{2}\right),(\mathbf{B})$ March MLD, (C) dLSW thickness (refer to dLSW definition in Fig. 3B), (D) Sea surface height. Numbered rows correspond to lag time in years, with $\operatorname{AMOC}\left(\sigma_{2}\right)_{\max }$ lagging for negative values and leading for positive values (i.e., time increases from top to bottom). All fields were detrended and low-pass filtered (see Materials and Methods). 

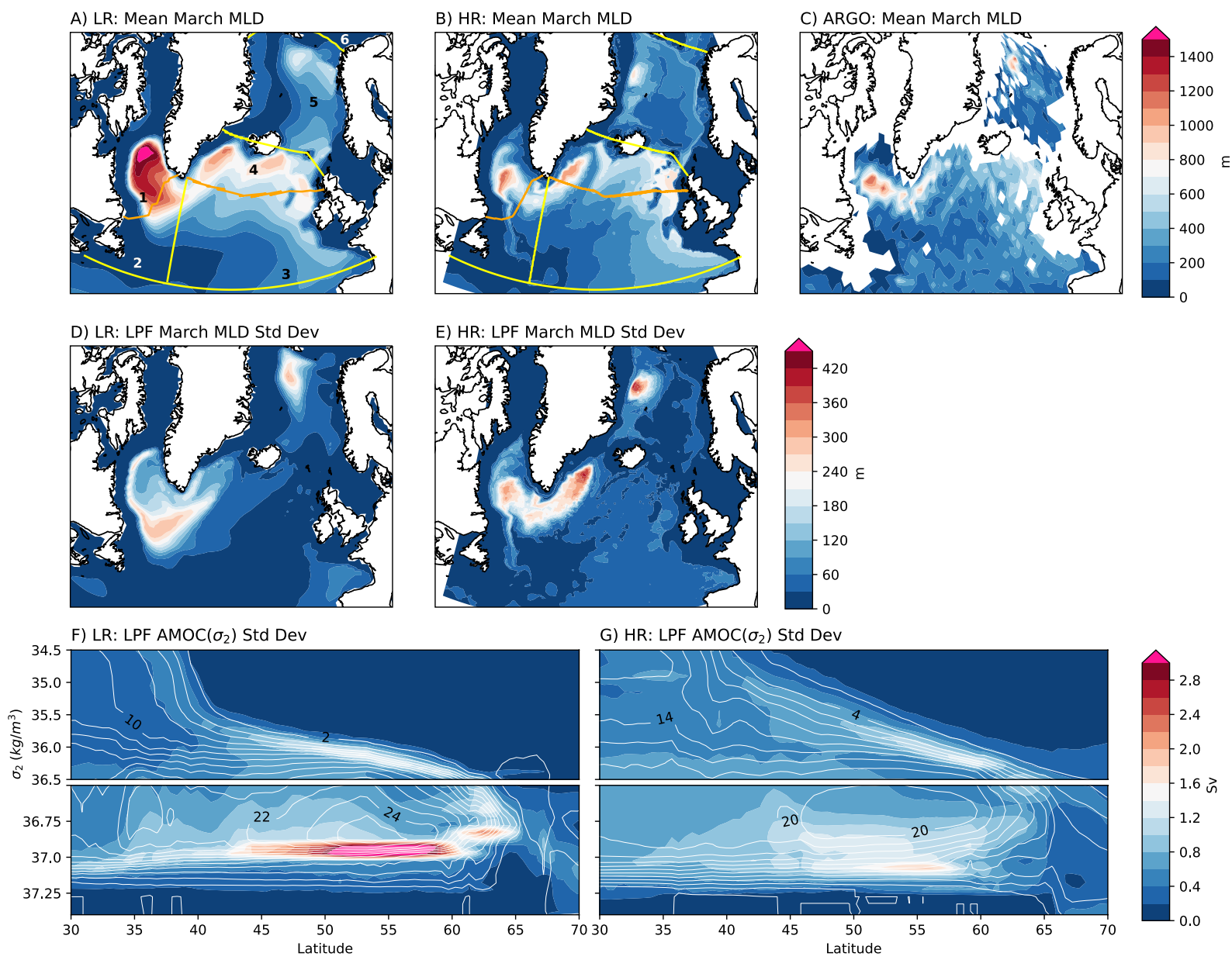

G) HR: LPF AMOC $\left(\sigma_{2}\right)$ Std Dev

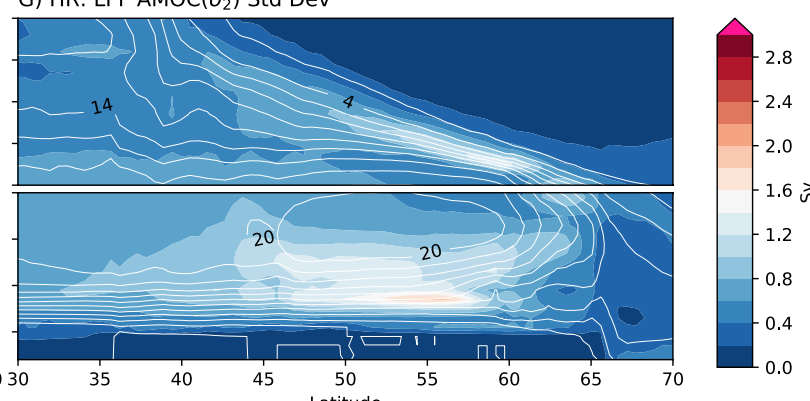

Fig. 1. Mean and LF Variability of March Deep Convection and AMOC. Climatological mean (average over simulation years 200-500) March mixed layer depth (MLD) from (A) LR and (B) HR. (C) Argo-based MLD climatology using a density threshold method (18). LF March MLD standard deviation from (D) LR and (E) HR. Climatological mean (contoured at $2 \mathrm{~Sv}$ intervals) and LF standard deviation (color fill) of $\operatorname{AMOC}\left(\sigma_{2}\right)$ from (F) LR and (G) HR. Orange lines in (A, B) show the locations of the OSNAP West and East arrays interpolated onto the model grid. Orange and yellow lines demarcate WMT regions north of $45^{\circ} \mathrm{N}$ referred to in the text as follows: 1. Labrador Sea (LAB), 2. Western subpolar gyre (SPG-west), 3. Eastern subpolar gyre (SPG-east), 4. Irminger Sea (IRM), 5. Greenland-Iceland-Norwegian Seas (GIN), and 6. Arctic Ocean (ARC). All fields were detrended and low-pass filtered (see Materials and Methods) prior to computation of standard deviation. 

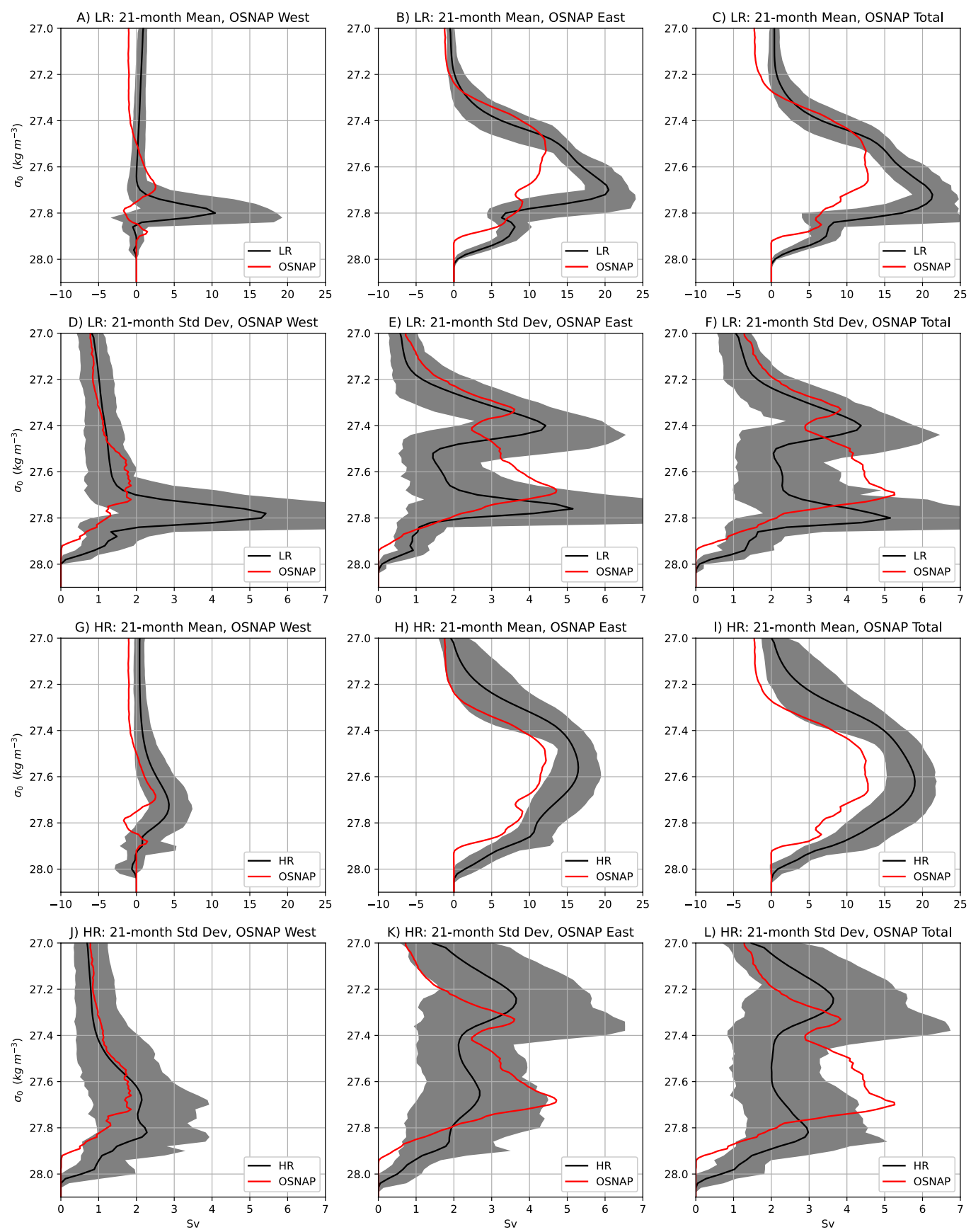

Fig. 2. Comparison to OSNAP overturning observations. (A-C) 21 -month mean overturning across OSNAP West, OSNAP East, and OSNAP Total from LR. (D-F) 21-month standard deviation of overturning across OSNAP West, OSNAP East, and OSNAP Total from LR. (G-L) Same as (A-F) but from HR. In each panel, OSNAP observations are shown in red, black curves show the model long-term mean statistics (corresponding to simulation years 200-500), and grey shading gives the min/max range of the statistic computed over rolling 21-month windows. 

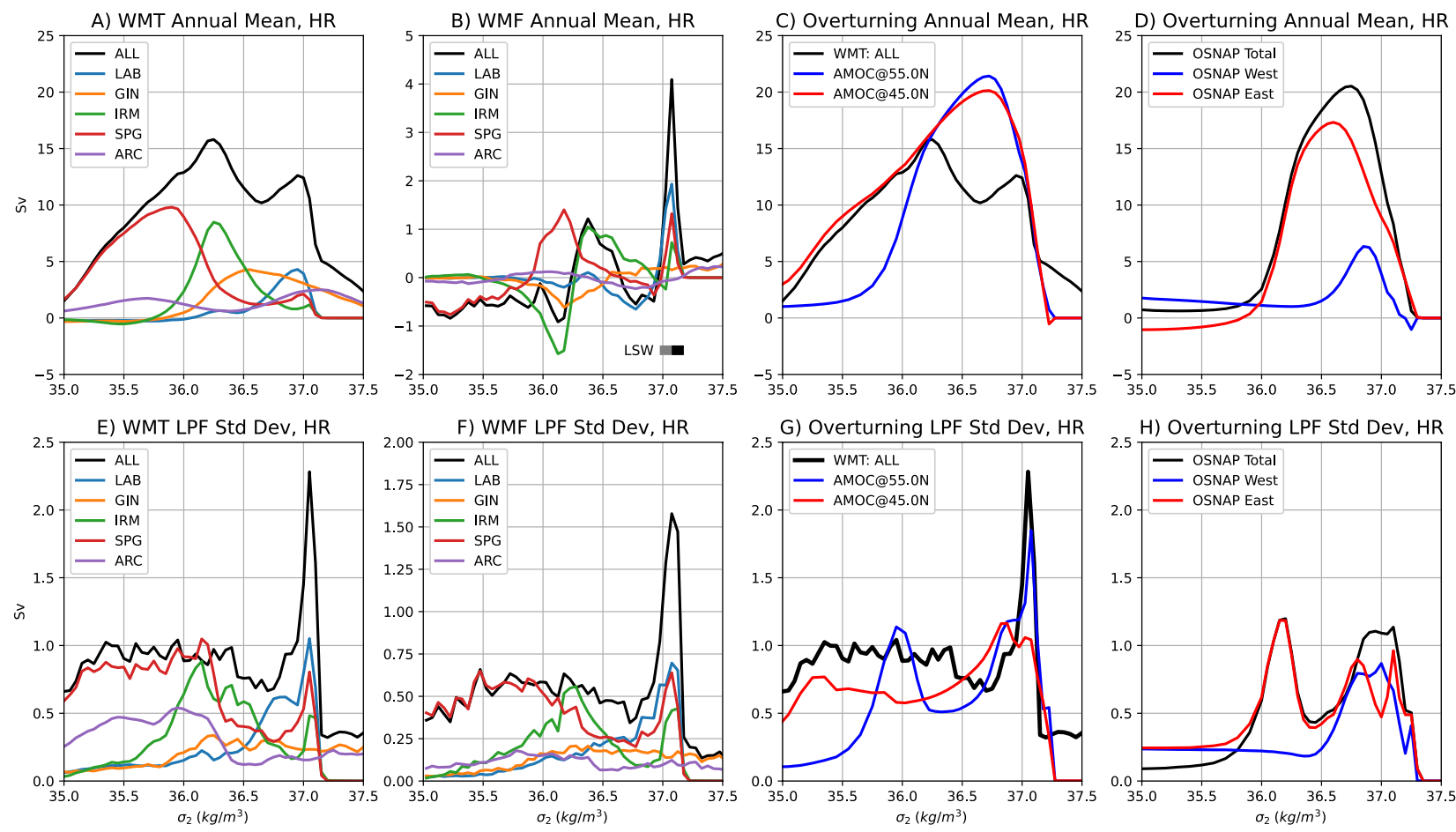

Fig. 3. Mean and Low-Frequency Variability of WMT, WMF, and MOC. Climatological mean (average over simulation years 200-500) (A) WMT, (B) WMF, (C) WMT compared to overturning at $45^{\circ} \mathrm{N}$ and $55^{\circ} \mathrm{N}$, and (D) overturning across OSNAP array lines. (E-H) LF standard deviation of overturning variables plotted in panels (A-D). All fields are from the HR simulation (see Fig. S1 for corresponding LR plot). The approximate density range of model Labrador Sea Water (LSW) is shown in panel (B), with the denser half of the range (in black) indicating deep LSW (dLSW). All fields were detrended and low-pass filtered (see Materials and Methods) prior to computation of standard deviation. 


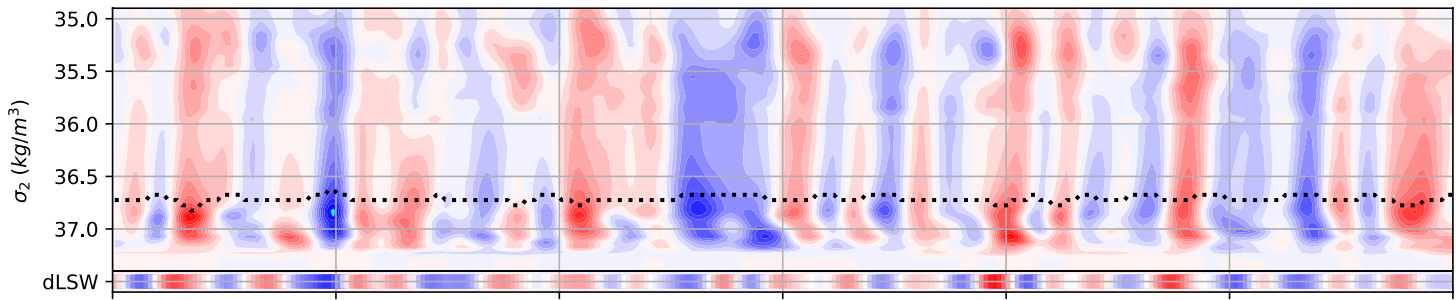

B) WMT (Region=ALL), HR

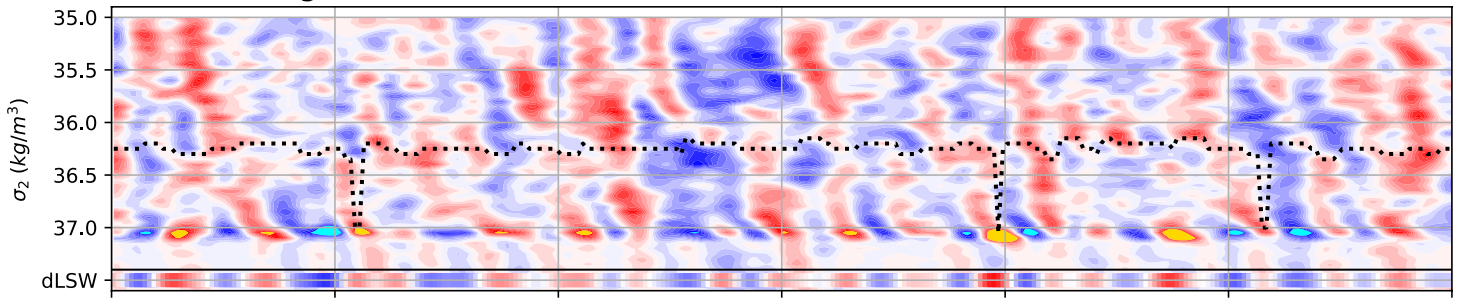

C) WMT (Region=IRM+GIN+SPG_east), HR

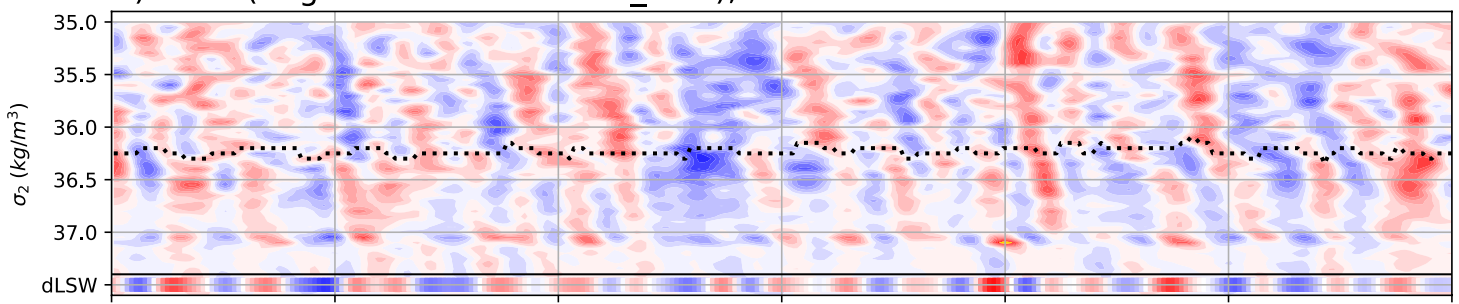

D) WMT (Region=LAB+SPG west), HR

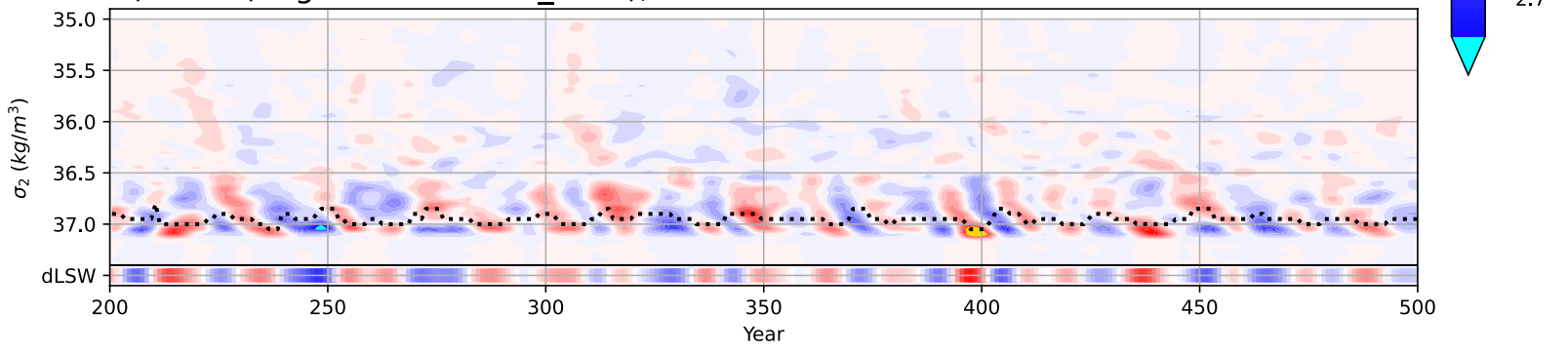

Fig. 4. Multidecadal Cycles of LSW Formation, Thermohaline Circulation, and Surface Transformation from HR. LF anomalies from years 200-500 of the HR simulation of: (A) $\operatorname{AMOC}\left(\sigma_{2}\right)$ at $45^{\circ} \mathrm{N},(\mathbf{B}) \mathrm{WMT}$ over all regions (north of $\left.45^{\circ} \mathrm{N}\right),(\mathbf{C}) \mathrm{WMT}$ over the Irminger, GIN, and SPG-east regions, (D) WMT over the Labrador and SPG-west regions. Bar contour at "dLSW" label on y-axis of each panel shows anomalous surface WMF of dLSW within the LAB region (note that it is the same in each panel). The dLSW formation timeseries is a sum over the $\sigma_{2}$ dimension (refer to Fig. 3B for the corresponding density range) and is plotted as a contour bar at the bottom of each panel to facilitate comparison with streamfunction anomalies. Dotted lines show the density corresponding to the time-varying maxima of the respective LF streamfunctions. All fields were detrended and low-pass filtered (see Materials and Methods). 

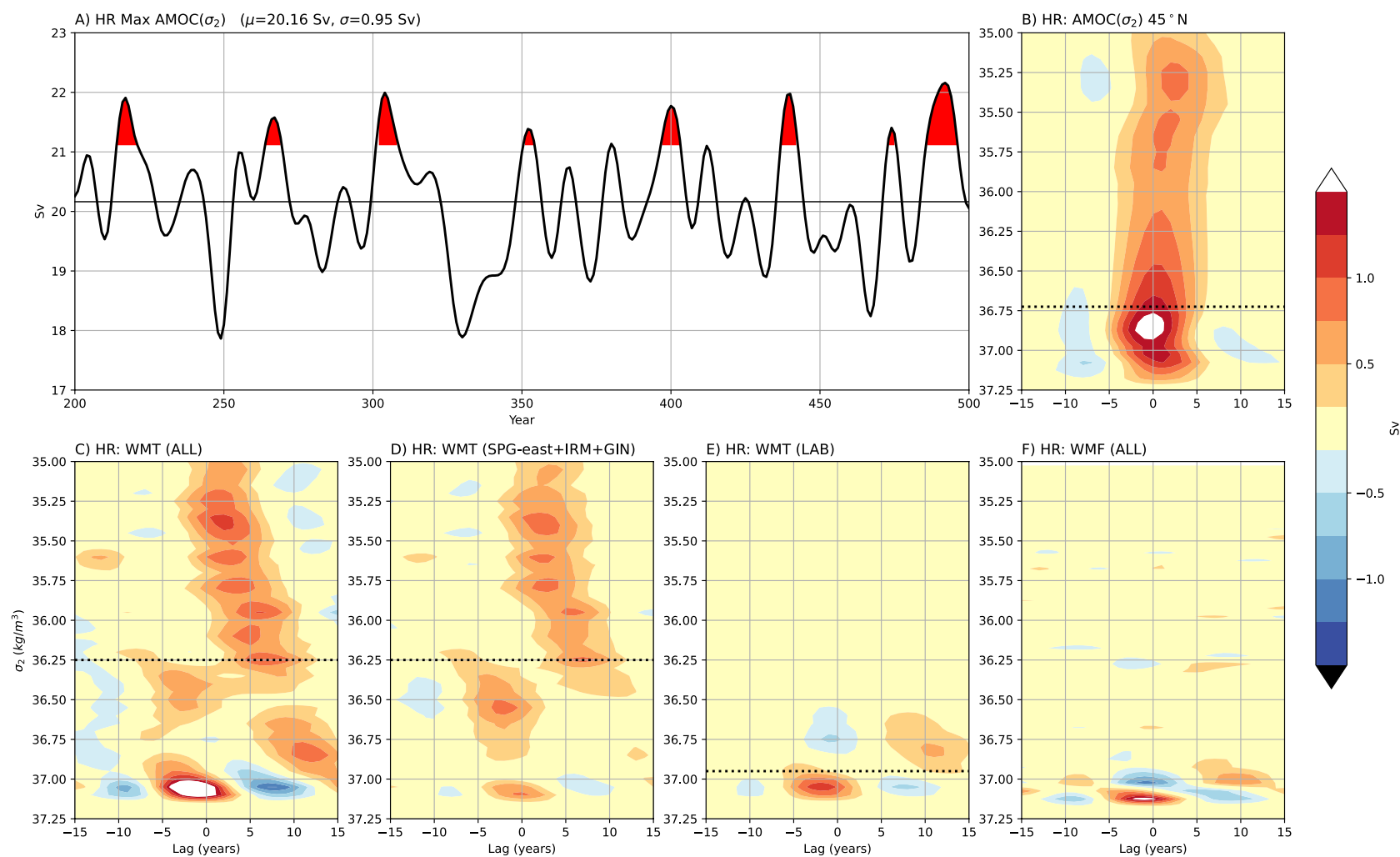

ڤั

Fig. 5. WMT and WMF anomalies associated with strong overturning at $45^{\circ} \mathrm{N}$. From $\mathrm{HR}$, lag composite anomalies corresponding to large positive $\operatorname{AMOC}\left(\sigma_{2}\right)$ strength anomalies. (A) Time series of detrended, $\operatorname{LF} \operatorname{AMOC}\left(\sigma_{2}\right)_{\max }$ at $45^{\circ} \mathrm{N}$ with red fill indicating time periods used in composite $(>+1 \sigma)$. Composites of: (B) AMOC $\left(\sigma_{2}\right)$ at $45^{\circ} \mathrm{N}$; (C) Total WMT north of $45^{\circ} \mathrm{N}$; (D) WMT in the eastern SPNA (combined IRM+GIN+SPG-east region); (E) WMT in the Labrador Sea (LAB region); (F) Total WMF north of $45^{\circ}$ N. Dashed black lines in panels (A, C-E) give the density where the respective mean overturning streamfunctions are maximum. $\operatorname{AMOC}\left(\sigma_{2}\right)_{\max }$ lags for negative values and leads for positive values along the $\mathrm{x}$-axis (i.e., time increases from left to right). All fields were detrended and low-pass filtered (see Materials and Methods). 

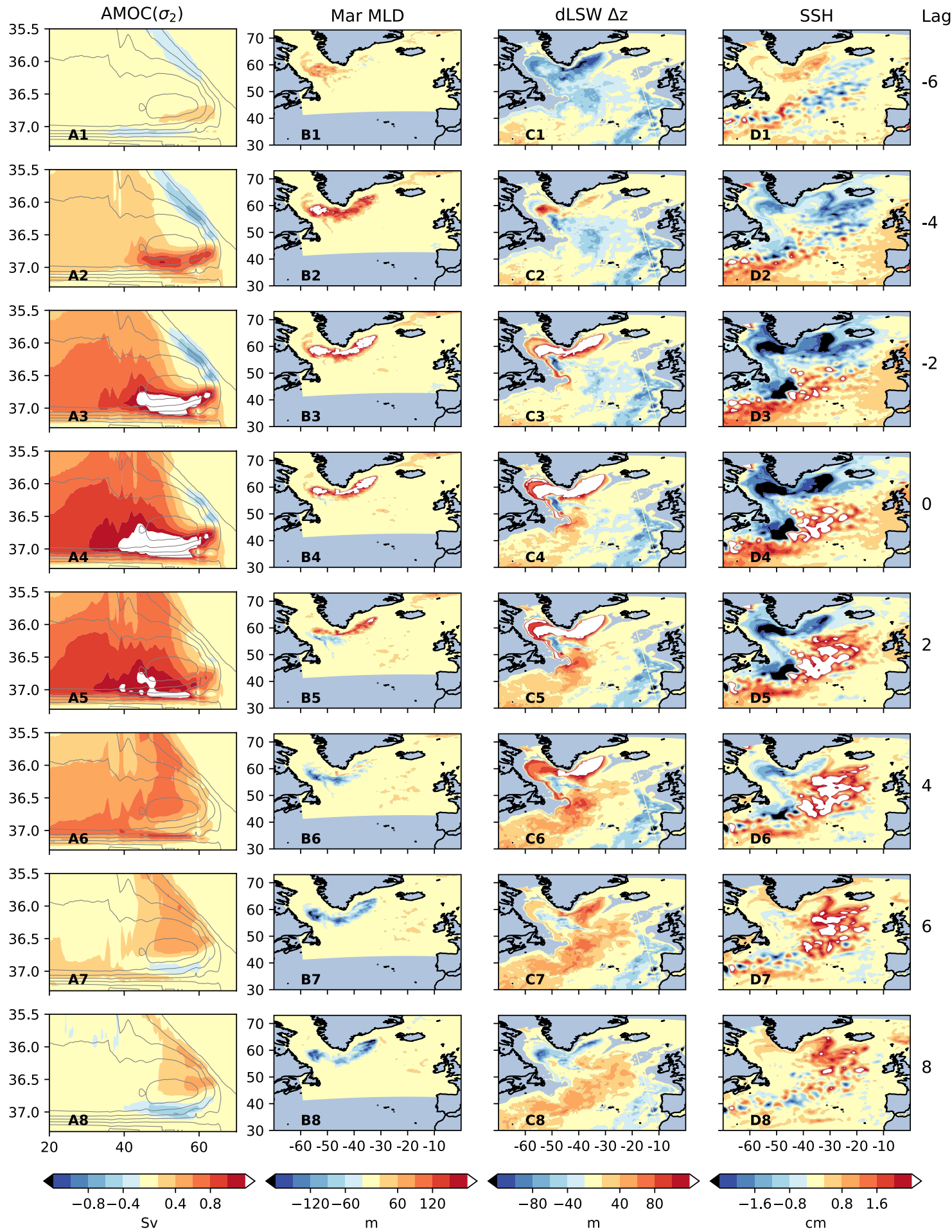

Fig. 6. SPNA anomalies associated with strong $\operatorname{AMOC}\left(\sigma_{2}\right)$ at $45^{\circ}$ N. From HR, lag composite anomalies corresponding to $\operatorname{AMOC}\left(\sigma_{2}\right)$ strength at $45^{\circ} \mathrm{N}$ (computed as the maximum in density space) exceeding +1 standard deviation (refer to time series shown in Figure $5 \mathrm{~A}$ ). (A)

$\operatorname{AMOC}\left(\sigma_{2}\right),(\mathbf{B})$ March MLD, (C) dLSW thickness (refer to dLSW definition in Fig. 3B), (D)

Sea surface height. Numbered rows correspond to lag time in years, with $\operatorname{AMOC}\left(\sigma_{2}\right)_{\max }$ lagging for negative values and leading for positive values (i.e., time increases from top to bottom). All fields were detrended and low-pass filtered (see Materials and Methods). 


\section{Materials and Methods}

\section{Model Simulations}

The simulations use the Community Earth System Model Version 1.3 (CESM1.3) code base (35) set up in low-resolution (LR; nominal $1^{\circ}$ horizontal resolution in each of the ocean, atmosphere, land, and sea ice components) and high-resolution (HR; nominal $0.1^{\circ}$ horizontal resolution in ocean and sea ice components, and nominal $0.25^{\circ}$ horizontal resolution in the atmosphere and land components) configurations. Both configurations use a spectral element dynamical core in the atmosphere component (Community Atmosphere Model version 5). The focus is on a pair of preindustrial control (1850 radiative conditions) simulations at HR and LR that were initialized from observed climatology and integrated for 500 years on the Sunway TaihuLight system $(17,18)$. Initial transients are avoided by excluding the first 199 years from the analysis.

\section{Mixed Layer Depth}

Model mixed layer depth (MLD) is defined using a maximum buoyancy gradient criterion (34) while observed MLD is defined using a variable density threshold method (19).

\section{Density-space AMOC}

The Atlantic meridional overturning circulation is often represented in simplified, reduceddimension form in terms of a zonally integrated streamfunction, either in depth coordinates (2) or density coordinates (3). AMOC in density coordinates is defined as follows:

$$
\operatorname{AMOC}(t, y, \sigma)=-\int_{\sigma_{\max }}^{\sigma} d \sigma \int_{x_{e}}^{x_{w}} v(t, y, x, \sigma) d x
$$

where $t$ is time, $y$ is latitude, $x$ is longitude, $\sigma$ is density, and $v$ is the meridional velocity. The zonal integral is performed across the basin from the western endpoint $\left(x_{w}\right)$ to the eastern endpoint $\left(x_{e}\right)$, and the vertical integral is performed from the maximum density $\left(\sigma_{\max }\right)$ to some lighter density $(\sigma)$. We primarily use $\sigma_{2}$ as the density coordinate (i.e., density referenced to $2000 \mathrm{~m}$ depth in units of $\mathrm{kg} \mathrm{m}^{-3}$, after subtracting $1000 \mathrm{~kg} \mathrm{~m}^{-3}$ ) but use $\sigma_{0}$ (referenced to $0 \mathrm{~m}$ depth) for comparison to OSNAP data. Note that computing $\operatorname{AMOC}\left(\sigma_{0}\right)$ across OSNAP array lines entails a coordinate transformation such that $v$ is the velocity normal to the array line and $x$ is the (nominally eastward) direction parallel to the array line.

\section{Surface Water Mass Transformation and Formation}

The ocean thermohaline circulation can be cast in terms of diapycnal water mass transformations related to surface forcing and interior mixing processes (21-23). The dominance of air-sea buoyancy exchange in driving the density-space overturning in the SPNA (24) makes surface water mass transformation analysis a powerful and popular tool for studying NADW production and AMOC variability in both observations $(6,25-27)$ and models $(24,28-32)$. As detailed in previous studies (e.g., 22), the surface density flux at the air-sea interface can be written as a function of the net surface heat $\left(Q\right.$; in units of $\left.\mathrm{W} \mathrm{m}^{-2}\right)$ and freshwater fluxes $(F$; in units of $\mathrm{kg}$ freshwater $\left.\mathrm{m}^{-2} \mathrm{~s}^{-1}\right)$ into the ocean as follows:

$$
f=-\frac{\alpha}{C_{p}} Q-\beta \frac{S}{1-S} F
$$

where $\alpha$ and $\beta$ are the (positive) thermal expansion and haline contraction coefficients, $C_{p}$ is the specific heat capacity of seawater, and $S$ is the sea surface salinity. The surface density flux, $f$ (in units of $\mathrm{kg}$ seawater $\left.\mathrm{m}^{-2} \mathrm{~s}^{-1}\right)$ is integrated over surface density outcrop regions $\left(d A_{\rho}\right.$, 
corresponding to densities in the range $\rho-\Delta \rho / 2 \rightarrow \rho+\Delta \rho / 2)$ to yield the water mass transformation (WMT; in units of $\mathrm{Sv}=10^{6} \mathrm{~m}^{3} \mathrm{~s}^{-1}$ ) as a function of density:

$$
\operatorname{WMT}(\rho)=\frac{1}{\Delta \rho} \iint f d A_{\rho}
$$

In practice, WMT is computed from monthly average $Q, F$, and $S$, and to facilitate direct comparison with the model $\operatorname{AMOC}\left(\sigma_{2}\right)$ streamfunction, the areal integration of $f$ is performed over outcrops of $\sigma_{2}$ (i.e., density referenced to $2000 \mathrm{~m}$ depth in units of $\mathrm{kg} \mathrm{m}^{-3}$, after subtracting $1000 \mathrm{~kg} \mathrm{~m}^{-3}$ ) where surface $\sigma_{2}$ is computed from monthly average sea surface temperature and salinity. Finally, the surface water mass formation (WMF; in $\mathrm{Sv}$ ) is given by the density-space convergence of the surface transformation:

$$
W M F\left(\sigma_{2}\right)=-\frac{d W M T}{d \sigma_{2}}
$$

\section{Statistical Analysis}

Low frequency (LF) variability of all fields is isolated using a $4^{\text {th }}$ order Butterworth low-pass digital filter with a cutoff period of 10 years. The statistical significance of composites was assessed using a two-sided Student's t-test which revealed that all the anomalies discussed in the text are significantly different from zero at the $95 \%$ confidence level (not shown). 

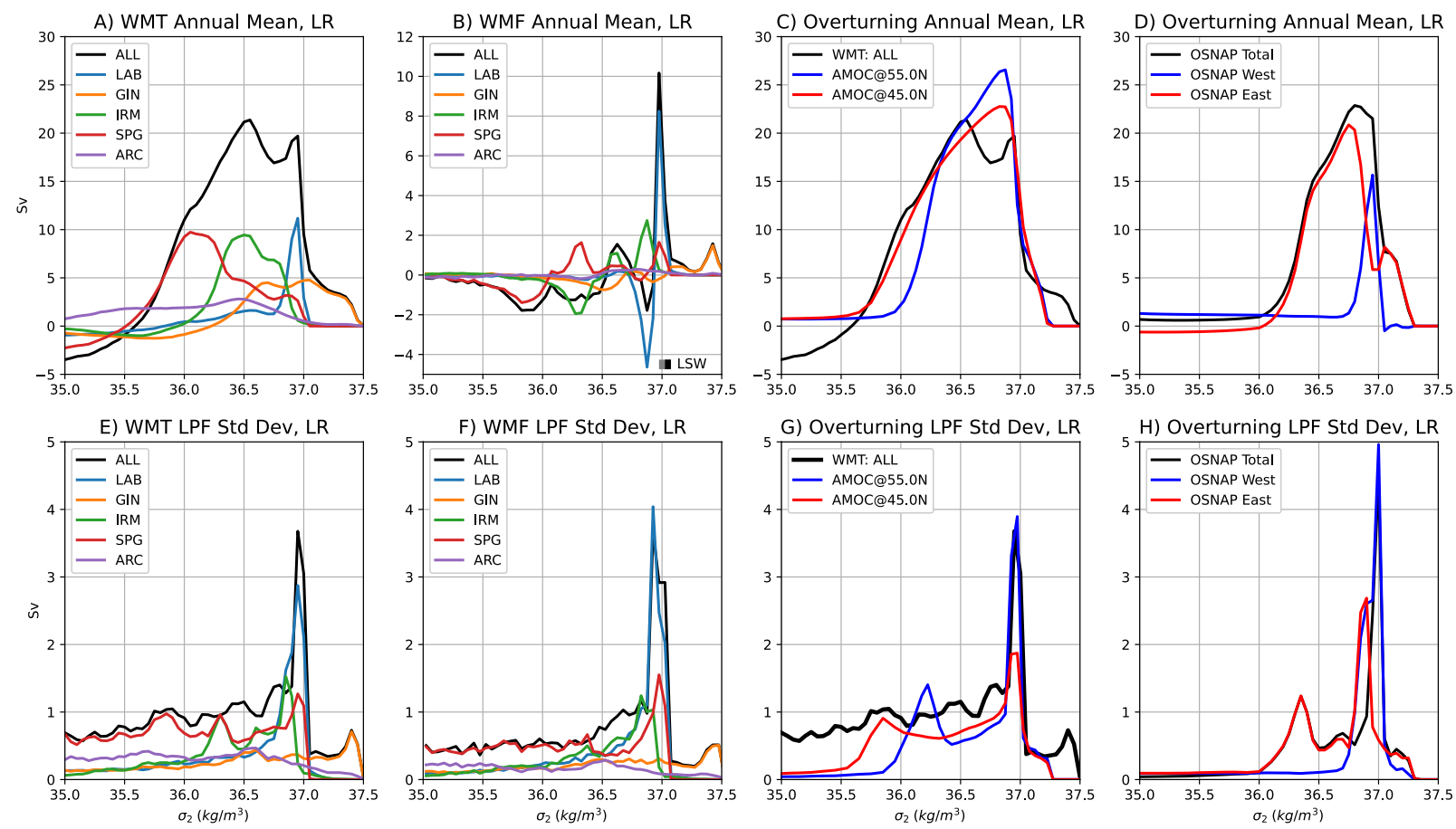

Fig. S1.

Mean and Low-Frequency Variability of WMT, WMF, and MOC. Equivalent to Fig. 3 of

Main Text but for LR. Climatological mean (average over simulation years 200-500) (A) WMT, (B) WMF, (C) WMT compared to overturning at $45^{\circ} \mathrm{N}$ and $55^{\circ} \mathrm{N}$, and (D) overturning across OSNAP array lines. (E-H) LF standard deviation of overturning variables plotted in panels (AD). The approximate density range of model Labrador Sea Water (LSW) is shown in panel (B), with the denser half of the range (in black) indicating deep LSW (dLSW). All fields were detrended and low-pass filtered (see Materials and Methods) prior to computation of standard deviation. 

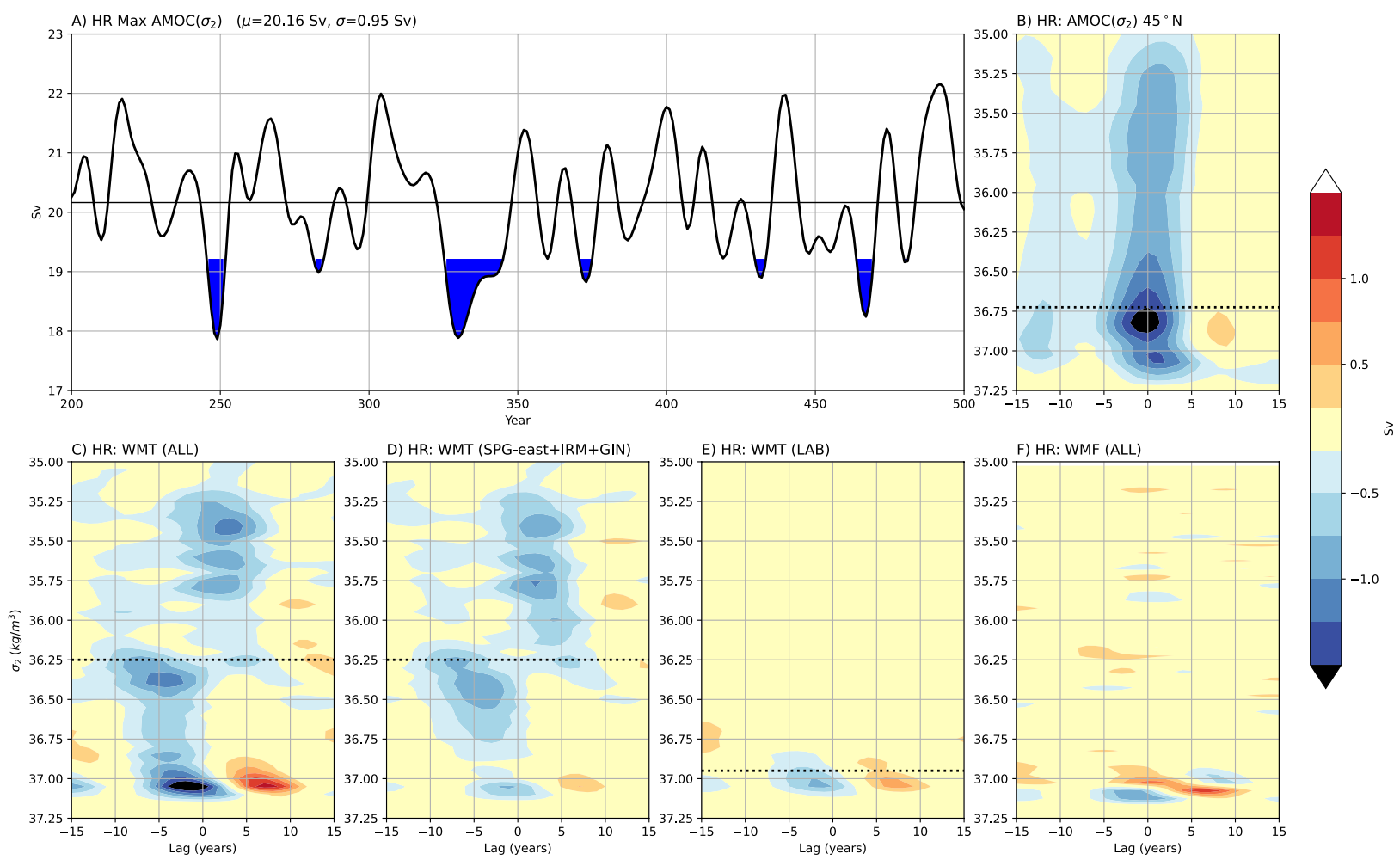

\section{Fig. S2.}

WMT and WMF anomalies associated with weak overturning at $45^{\circ} \mathrm{N}$. From $\mathrm{HR}$, lag composite anomalies corresponding to large negative $\operatorname{AMOC}\left(\sigma_{2}\right)$ strength anomalies. (A) Time series of detrended, $\operatorname{LF} \operatorname{AMOC}\left(\sigma_{2}\right)_{\max }$ at $45^{\circ} \mathrm{N}$ with blue fill indicating time periods used in composite $(<-1 \sigma)$. Composites of: $(\mathbf{B}) \operatorname{AMOC}\left(\sigma_{2}\right)$ at $45^{\circ} \mathrm{N} ;(\mathbf{C})$ Total WMT north of $45^{\circ} \mathrm{N}$; (D) WMT in the eastern SPNA (combined IRM+GIN+SPG-east region); (E) WMT in the Labrador Sea (LAB region); (F) Total WMF north of $45^{\circ} \mathrm{N}$. Dashed black lines in panels (A, C-E) give the density where the respective mean overturning streamfunctions are maximum. AMOC $\left(\sigma_{2}\right)_{\max }$ lags for negative values and leads for positive values along the x-axis (i.e., time increases from left to right). All fields were detrended and low-pass filtered (see Materials and Methods). 